\title{
Heat inactivation of Listeria innocua in broth and food products under non-isothermal conditions
}

\author{
Fátima A. Miller ${ }^{\mathrm{a}}$, Bárbara F. Ramos ${ }^{\mathrm{a}}$, Maria M. Gil ${ }^{\mathrm{a}, \mathrm{b}}$, Teresa R.S. Brandão ${ }^{\mathrm{a}}$, Paula Teixeira ${ }^{\mathrm{a}}$, \\ Cristina L.M. Silva ${ }^{\mathrm{a}, *}$ \\ a CBQF/Escola Superior de Biotecnologia, Universidade Católica Portuguesa, Rua Dr. António Bernardino de Almeida, 4200-072 Porto, Portugal \\ ${ }^{\mathrm{b}}$ GIRM - Marine Resources Research Group, Polytechnic Institute of Leiria, Campus 4, Santuário $N^{a}$ Sr $^{a}$ dos Remédios, Apartado 126, 2524-909 Peniche, Portugal
}

\begin{abstract}
A B S T R A C T
The objective of this work was to study the effect of three linear temperature profiles (heating rates of $1.5,1.8$ and $2.6{ }^{\circ} \mathrm{C} / \mathrm{min}$, from 20 to $65^{\circ} \mathrm{C}$ ) on Listeria innocua inactivation in liquid medium. The inactivation was also analyzed in artificially contaminated parsley (heating rate of $1.8^{\circ} \mathrm{C} / \mathrm{min}$ ) and throughout a frying process, using a pre-cooked frozen food as case study. Inactivation showed a sigmoidal behaviour and all data was fitted with a Gompertz-inspired model. Results demonstrated that, in liquid media, Listeria inactivation is influenced by the temperature profile used. As heating rate increases, the shoulder decreases and the tail effect disappears. If Listeria was in parsley, its heat resistance increased (for identical experimental conditions in broth). Besides model adequacy was proven in all studied situations, the heating rate affected parameters' precision.
\end{abstract}

\section{Introduction}

Listeria monocytogenes is an actual concern in food contamination due to its ubiquitous characteristics and pathogenicity. In many situations, Listeria innocua is elected as the non-pathogenic specie to be used as a surrogate for L. monocytogenes (Kamat \& Nair, 1996; Margolles, Mayo, \& Reyes-Gavilán, 2000; Piyasena, Liou, \& McKellar, 1998). Because of the occurrence of Listeria spp. in thermally processed products, studies on the evaluation of its heat resistance are of main importance. Listeria can grow at refrigeration temperatures and can even survive in frozen conditions. This is also a concern for pre-cooked meals.

Much work has been done at laboratory scale to clarify the Listeria behaviour during a heat treatment. In this situation, environmental factors (such as temperature, water activity, $\mathrm{pH}$, etc.) can be easily controlled. The microbial response to these stressing factors is, in many cases, attained in broth. If the microorganism is present in a food, its behaviour will be certainly different due to food constituents' characteristics, surface topology and microbial adhesion.

When realistic food processing conditions occur (pasteurisation is one example that includes a come-up time), the temperature history affects the microbial behaviour. Bacteria submitted to

\footnotetext{
* Corresponding author. Tel.: +351 22 5580058; fax: +351 225090351. E-mail address: clsilva@esb.ucp.pt (C.L.M. Silva).
}

non-isothermal conditions (i.e. temperature rises throughout the process time till a target value) are more heat resistant than bacteria treated isothermally. The imposed stresses will determine the protective cell response (Marechal, Martínez de Marnañón, Poirier, \& Gervais, 1999).

If results obtained isothermally are used for predictions in dynamic temperature conditions, hazardous under-estimations of microbial load may occur (thus compromising safety). Studies on this topic are clearly important.

One interesting case, in which temperature rising directly affects microbial viability, is the pre-cooked foods branch. Frying is one example of the thermal processes involved, and studies on microbial inactivation via frying are an interesting field. Usually, foods are fried until its centre has received enough heat to destroy possible contaminant microorganisms and/or to change desired sensory properties. In immersion oil frying, the medium is heated to high temperatures $\left(\cong 180^{\circ} \mathrm{C}\right)$, resulting in reduced processing time. This can be a problem when the frying product is frozen (the cases of pre-cooked meals stored under frozen conditions). The time of frying may not be enough for the coldest point to reach the required temperatures. In situations of contamination in a pre-frozen stage, serious outbreaks may occur.

The heat resistance of microorganisms is often assessed by calculation of $D$-values (i.e. the time needed to reduce the population by $90 \%$ ). However, this approach becomes restricted in situations where survival curves deviate from log-linearity. Depending on the environmental conditions, the survival curves 
may exhibit a sigmoidal shape with an initial delay period (or shoulder), followed by a maximum inactivation rate tending to a residual tail population. It is not consensual whether the tail is an actual observed heat resistant population or an experimental limitation of the enumeration procedure. However, in literature, some kinetic models have been applied and discussed aiming at describing conveniently such tendencies (Cole, Davies, Munro, Holyoak, \& Kilsby, 1993; Juneja \& Eblen, 1999; Juneja \& Marks, 2003; Murphy, Marks, Johnson, \& Johnson, 2000; Peleg, Penchina, \& Cole, 2001). Among the models used, Gompertz-inspired functions have been successfully applied in sigmoidal inactivation kinetics, both in isothermal and time-varying temperature conditions (Bhaduri et al., 1991; Gil, Brandão, \& Silva, 2006; Linton, Carter, Pierson, \& Hackney, 1995).

The objectives of this study were: (i) to evaluate the influence of different time-varying temperature processes (with different heating rates) on inactivation kinetics of L. innocua in broth, (ii) to compare the bacterium kinetics in broth and in a food (parsley) using identical non-isothermal conditions, and (iii) to follow the survival of $L$. innocua during an entire frying process of a frozen pre-cooked product (meat pockets used as case study).

\section{Materials and methods}

\subsection{Experimental procedures}

\subsubsection{Cultures}

L. innocua NCTC 10528 was subcultured $\left(30^{\circ} \mathrm{C}, 24 \mathrm{~h}\right)$ in Tryptic Soy Broth - TSB (Lab M, Lancashire, UK) containing $0.6 \%$ yeast extract - TSBYE (Lab M). Cultures were maintained at $7{ }^{\circ} \mathrm{C}$ on Tryptic Soy Agar - TSA (Lab M) supplemented with $0.6 \%$ yeast extract - TSAYE.

\subsubsection{Preparation of cultures}

The second subculture of $L$. innocua was incubated at $30^{\circ} \mathrm{C}$ for $20 \mathrm{~h}$ to yield stationary phase cultures. This cell growth phase was chosen due to its higher stress resistance than exponential phase cells (Miller, Gil, Brandão, Teixeira, \& Silva, 2009).

Cells in each cellular suspension were enumerated by plating appropriate dilutions, in duplicate, on the three solid media studied.

\subsubsection{Heat treatments}

2.1.3.1. Temperature profiles. Heat treatments were carried out in a thermostatic bath (Julabo ${ }^{\circledR}$ FP40, Seelbach, Germany) with a temperature programmer (Julabo ${ }^{\circledR}$ HC-E07, Seelbach, Germany).

Three temperature profiles were assumed, with temperatures varying from approximately $20-65^{\circ} \mathrm{C}$ at linear increasing rates; $T$ $\left({ }^{\circ} \mathrm{C}\right)=21.6+\beta \cdot t(\min )$. The media temperature was then held at $65.0^{\circ} \mathrm{C}$ for different periods of time, depending on the heating rate considered: (a) $\beta=1.5^{\circ} \mathrm{C} \mathrm{min}^{-1}$ (followed by $20 \mathrm{~min}$ at $\sim 65.0^{\circ} \mathrm{C}$ ); (b) $\beta=1.8^{\circ} \mathrm{C} \mathrm{min}^{-1}$ (followed by $10 \mathrm{~min}$ at $\sim 65.0^{\circ} \mathrm{C}$ ); (c) $\beta=2.6^{\circ} \mathrm{C} \mathrm{min}^{-1}$ (followed by $12 \mathrm{~min}$ at $\sim 65.0^{\circ} \mathrm{C}$ ).

The temperature profiles correspond to actual temperatures measured in broth/food using K-type thermocouples $\left( \pm 0.2^{\circ} \mathrm{C}\right)$.

2.1.3.2. Experiments in broth. $99 \mathrm{ml}$ of TBSYE, used as heating medium, were dropped in an Erlenmeyer flask, which was immersed in the water bath and inoculated with $1 \mathrm{ml}$ of cell suspension. The samples were continuously agitated, using a magnetic stirrer, removed at different time intervals and placed in a mixture of ice-water for posterior cell enumeration.

There was a control for each experiment, which consisted of another $99 \mathrm{ml}$ of TSBYE inoculated with $1 \mathrm{ml}$ of the same cellular suspension and incubated at $30^{\circ} \mathrm{C}$ for the same time. The initial concentration of $L$. innocua was approximately $10^{7} \mathrm{cfu} / \mathrm{ml}$.

Three replicates of all these experiments were performed.

\subsubsection{Experiments in foods}

2.1.3.3.1. Parsley. Parsley (Petroselinum crispum) samples were artificially inoculated by immersion in a bacterial suspension with approximately $10^{7} \mathrm{cfu} / \mathrm{ml}$, for approximately $10 \mathrm{~s}$. The samples were sealed and vacuum-packaged (Multivac A300/41/42, Wolfertschwenden, Germany) in sterilized bags. These were immersed in the thermostatic agitated water bath and subjected to a heat treatment corresponding to the temperature profile $(b)$. Thermocouples were placed inside the plastic bags to measure actual temperature profile in parsley samples. Bags were positioned such that entire parsley samples were submerged and each bag was removed at different time intervals and placed in a mixture of ice-water. For each time, sterile peptone water was added to approximately $3 \mathrm{~g}$ of parsley and bags were pummelled for $4 \mathrm{~min}$ in a stomacher at normal speed. Cell enumeration was then carried out.

Uncontaminated parsley and contaminated parsley samples, which were not submitted to heat treatment, were used as controls.

2.1.3.3.2. Meat pockets. Commercially available frozen meat pockets (i.e. dough stuffed with sliced cooked pork and beef; it is a frozen pre-cooked product that should be fried before consumption) were artificially contaminated with Listeria inoculums, by injecting in the centre of the product $250 \mu \mathrm{l}$ of the bacterial suspension with approximately $10^{7} \mathrm{cfu} / \mathrm{ml}$. The meat pockets were maintained at $-8{ }^{\circ} \mathrm{C}$ for $1 \mathrm{~h}$, prior to the heating process. Frozen meat pockets were fried in a common fryer at $180^{\circ} \mathrm{C}$ (oil temperature) for a maximum of $8 \mathrm{~min}$. The temperature history was monitored during the whole frying process using K-type thermocouples, placed in the centre of the samples. The values were recorded using a squirrel data logger (Grant Instruments 1023, Cambridge, England).

Samples (one sample is one meat pocket) were removed at different time intervals, placed in sterilized plastic bags and immersed in a mixture of ice-water. The meat of each sample was removed from the meat pocket and mixed with sterile peptone water in a stomacher bag, where it was blended by a Stomacher. Cell enumeration was then carried out.

Uncontaminated frozen meat pocket and contaminated frozen meat pocket that was not subjected to frying process were used as controls.

Three replicates of the frying process were performed.

\subsubsection{Enumeration}

Samples from heat treatments in liquid medium were serially diluted and plated in duplicate onto three different media: (i) TSAYE, (ii) TSAYE supplemented with $5 \%(\mathrm{w} / \mathrm{v})$ sodium chloride TSAYE $+\mathrm{NaCl}$ and (iii) Palcam Agar plus selective supplement (Miller, Brandão, Teixeira, \& Silva, 2006). Samples from heat treatments in food products (parsley and meat pockets) were also diluted and plated in duplicate, but only in Palcam Agar plus selective supplement due to the presence of natural food microflora.

All plates were incubated at $30^{\circ} \mathrm{C}$ and counted each $24 \mathrm{~h}$ during 5 days, or until the number of colony formation units no longer increased.

Average values of bacterial counts, from duplicate plate samples, were converted to log numbers for each combination.

\subsection{Modelling procedures}

\subsubsection{The inactivation model}

Assuming that the microbial thermal inactivation follows a sigmoidal behaviour, isothermal experimental data can be 
mathematically described by a re-parameterized Gompertzinspired model (Bhaduri et al., 1991; Char, Guerrero, \& Alzamora, 2009; Gil et al., 2006; Huang, 2009; Linton et al., 1995):

$\log \left(\frac{N}{N_{0}}\right)_{\text {isothermal }}=\log \left(\frac{N_{\text {res }}}{N_{0}}\right) \exp \left(-\exp \left(\frac{-k_{\text {max }} e}{\log \left(\frac{N_{\text {res }}}{N_{0}}\right)}(L-t)+1\right)\right)$

where $N$ is the microbial cell density at a particular process time, $t$. The indexes 0 and res indicate initial and residual (or tail) microbial cell density, respectively. The model parameters are $L$ (initial shoulder), $k_{\max }$ (maximum inactivation rate) and $\log \left(N_{\text {res }} / N_{0}\right)$ (tail).

The versatility of fitting linear data and those that contain shoulder and/or tailing effects make Gompertz one attractive model.

Microbial kinetic parameters are temperature dependent. Such dependence has been extensively studied and several models have been proposed in literature.

In relation to shoulder, the following polynomial equation was used (Ratkowsky, Olley, McMeekin, \& Ball, 1982):

$L=c(T-d)^{2}$

with $c$ and $d$ parameters.

The dependence of $k_{\max }$ on temperature was expressed by the well-known Arrhenius behaviour, using a finite reference temperature $\left(T_{\text {ref }}\right)$ to reduce parameters' collinearity (Cohen, Birk, Mannheim, \& Saguy, 1994; Haralampu, Saguy, \& Karel, 1985; Van Boekel, 1996):

$k_{\text {max }}=k_{\text {ref }} \exp \left(-\frac{\mathrm{Ea}}{R}\left(\frac{1}{T}-\frac{1}{T_{\text {ref }}}\right)\right)$

where $k_{\text {ref }}$ is the inactivation rate at a finite reference temperature, Ea the activation energy and $R$ the universal gas constant.

For non-isothermal conditions, temperature varies with time (i.e. dynamic temperature conditions). The number of log cycles reduction (in relation to initial load), at a particular time, can be calculated by encompassing the time-temperature effect as follows:

$\log \left(\frac{N}{N_{0}}\right)_{\text {non-isothermal }}=\int_{0}^{t} \frac{\mathrm{d}\left(\log \left(\frac{N}{N_{0}}\right)_{\text {isothermal }}\right)}{\mathrm{d} t} \mathrm{~d} t^{\prime}$

In such conditions, $L$ and $k_{\max }$ are time dependent and the previous expression derives to:
The simplex algorithm (Nelder \& Mead, 1965) was used to minimise the sum of the squares of the residuals.

The quality of the regression was evaluated by the coefficient of determination $\left(R^{2}\right)$, randomness and normality of the residuals.

Parameters' precision was evaluated by the standardised half width (SHW) at $95 \%$, i.e. halved confidence interval divided by the estimate $\equiv\left(\right.$ confidence interval $\left.{ }_{95 \%} / 2\right) \times(1 /$ estimate $) \times 100$.

All regression analysis procedures and calculations were performed in programs specially written in FORTRAN 77 language (Fortran 5.1, Microsoft Corporation ${ }^{\circledR}$, 1990) and Microsoft ${ }^{\circledR}$ Excel 2000 (Microsoft Corporation, USA).

\section{Results and discussion}

The experimental inactivation data of $L$. innocua in broth (TSBYE) and fitted curves are included in Fig. 1. When the heating treatment with temperature profile (a) was applied (lower heating rate of $1.5^{\circ} \mathrm{C} / \mathrm{min}$ ), the temperature of $65^{\circ} \mathrm{C}$ was attained in approximately $31 \mathrm{~min}$ (Fig. 1(a)). At this time, and depending on the enumeration media considered, different results were observed. L. innocua decreased 1.7, 2.5 and $4.4 \log$ cycles respectively, if TSAYE, Palcam Agar and TSAYE $+\mathrm{NaCl}$ were used.

If temperature profile (b) was applied (heating rate of $1.8^{\circ} \mathrm{C} / \mathrm{min}$ ), the temperature of $65{ }^{\circ} \mathrm{C}$ was attained in approximately $25 \mathrm{~min}$ (Fig. 1(b)). In this case, Listeria cells decreased 2.5, 4.0 and $4.4 \mathrm{log}$, when enumeration was performed on TSAYE, Palcam Agar and TSAYE $+\mathrm{NaCl}$, respectively.

In the case of temperature profile (c) (heating rate of $2.6^{\circ} \mathrm{C} / \mathrm{min}$ ), 18 min were necessary to achieve $65^{\circ} \mathrm{C}$ (Fig. 1(c)). The log cycles reductions were 1.6, 2.3 and 4.5 on TSAYE, Palcam Agar and TSAYE $+\mathrm{NaCl}$, respectively.

It is notorious the effect of the heating rate on the induced heat resistance of $L$. innocua, assessed by the sigmoidal tendency of the inactivation kinetics. As heating rate increases, the shoulder decreases and the tail effect disappears. This was observed for all media considered. In Fig. 2, this effect can be better visualized for the case of TSAYE medium.

Valdramidis, Geeraerd, Bernaerts, and Van Impe (2006) obtained similar conclusions for the inactivation of Escherichia coli, applying heating rates from 0.15 to $1.64{ }^{\circ} \mathrm{C} / \mathrm{min}$ (in the range $30-55^{\circ} \mathrm{C}$ ). These authors reported that microbial heat resistance was utmost perceived if the lowest heating rates were considered (with a corresponding comeup time higher than $30.61 \mathrm{~min}$ ). This was also observed by Marechal et al. (1999) in the case of Saccharomyces cerevisiae, when linear

$\log \left(\frac{N}{N_{0}}\right)_{\text {non-isothermal }}=\int_{0}^{t}\left[-k_{\max }\left(t^{\prime}\right) e \exp \left(-\frac{k_{\max }\left(t^{\prime}\right) e}{\log \left(\frac{N_{\text {res }}}{N_{0}}\right)}\left(L\left(t^{\prime}\right)-t^{\prime}\right)+1\right) \exp \left(-\exp \left(-\frac{k_{\max }\left(t^{\prime}\right) e}{\log \left(\frac{N_{\text {res }}}{N_{0}}\right)}\left(L\left(t^{\prime}\right)-t^{\prime}\right)+1\right)\right)\right] \mathrm{d} t^{\prime}$

If the temperature history $T(t)$ is known, the model valid for non-isothermal conditions can be obtained by merging Eqs. (2), (3) and (5) (Gil et al., 2006).

\subsubsection{Data analysis}

The parameters of the Gompertz-inspired inactivation model for non-isothermal conditions, i.e. $k_{\text {ref, Ea, }} c, d$ and $\log \left(N_{\text {res }} / N_{0}\right)$, were estimated by non-linear regression analysis, fitting Eq. (5) to experimental data. The reference temperature in the Arrhenius equation was considered equal to $58.5^{\circ} \mathrm{C}$. temperature increases with heating rates from 0.21 to $1.04{ }^{\circ} \mathrm{C} / \mathrm{min}$ (in the range $25-50^{\circ} \mathrm{C}$ ), were used. Ramos et al. (2001) explained these facts by the synthesis of a series of heat shock proteins (HSPs) induced by stressing temperature variations. Other microbial protective responses can be explained by modifications of the permeability of cells' membrane and by changes on cellular internal solute composition (Marechal et al., 1999). All these changes provide microbial potential ability to withstand lethal temperatures.

It was assumed that during heating-up phases no microbial growth occurred and there was a temperature limit below which no 

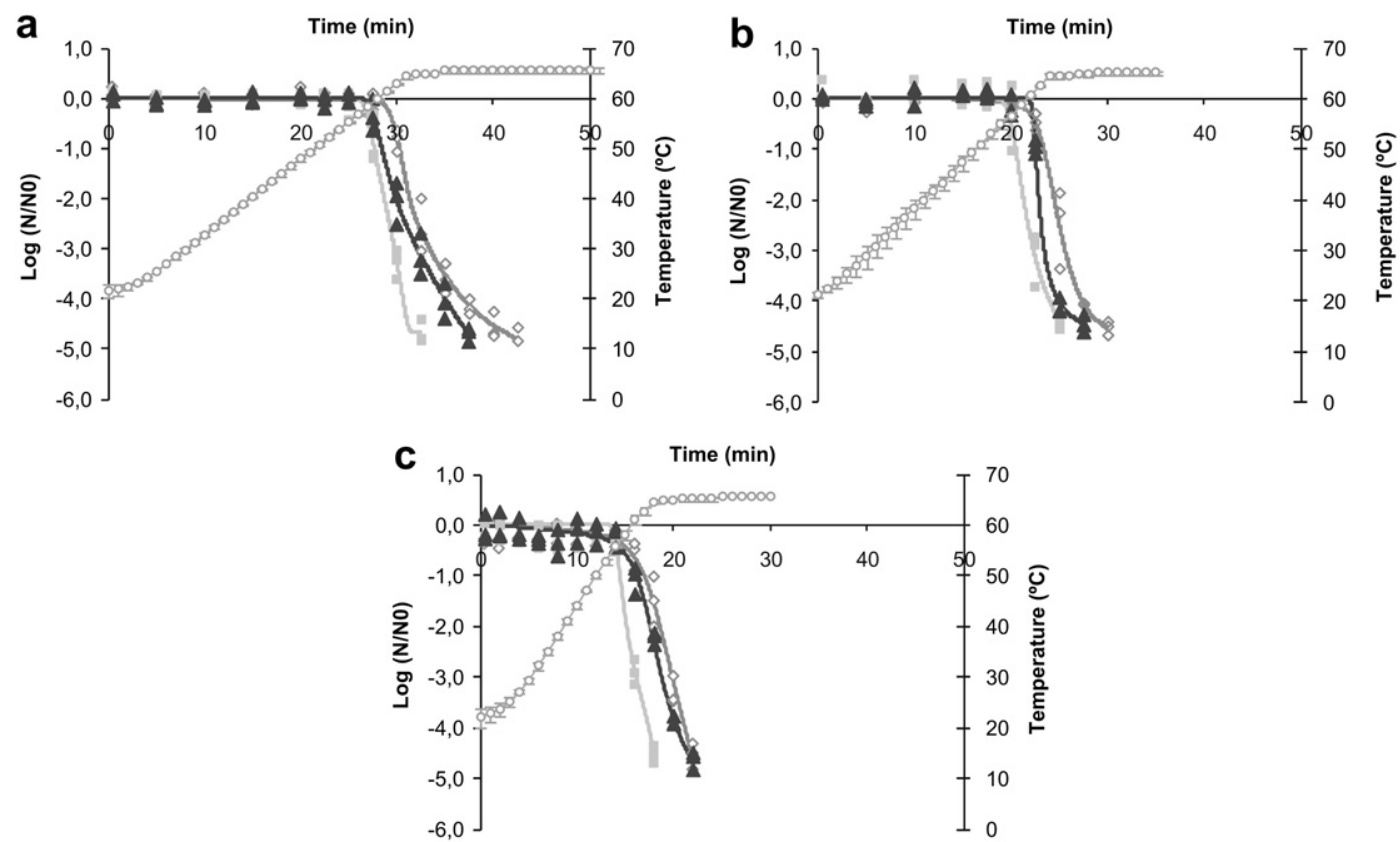

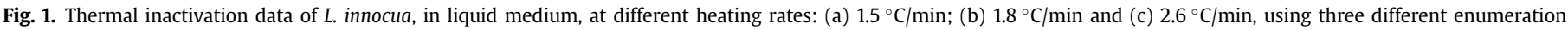
media: $(\diamond)$ TSAYE, $(\boldsymbol{\Delta})$ Palcam Agar and $(\square)$ TSAYE $+\mathrm{NaCl}$. Solid lines represent model fits. The bars represent the standard deviation of the temperature histories $(\bigcirc)$.

inactivation was verified. It was observed that this temperature limit was dependent on the enumeration media and on the heating rate. As the heating rate increased, this limit became lower; if TSAYE $+\mathrm{NaCl}$ medium was used, this was the lowest limit observed. For the lowest temperature increasing rate (of $1.5^{\circ} \mathrm{C} / \mathrm{min}$ ), inactivation started at $62{ }^{\circ} \mathrm{C}$ if TSAYE was used and at $58^{\circ} \mathrm{C}$ if TSAYE $+\mathrm{NaCl}$ was chosen. For the highest temperature increasing rate (of $2.6^{\circ} \mathrm{C} / \mathrm{min}$ ), Listeria inactivation began at $56^{\circ} \mathrm{C}$, independently of the enumeration media selected.

It is known that selective media do not inhibit the growth of undamaged cells but prevent the growth of injured cells (Miller et al., 2006). In the case of TSAYE $+\mathrm{NaCl}$, a lower count of Listeria means that the cytoplasmic membrane of the cells has been probably damaged. The presence of $\mathrm{LiCl}$ in Palcam Agar inactivates bacterial enzymes by the replacement of divalent cations by $\mathrm{Li}^{+}$ (Mendonca \& Knabel, 1994). Attending on the results presented in

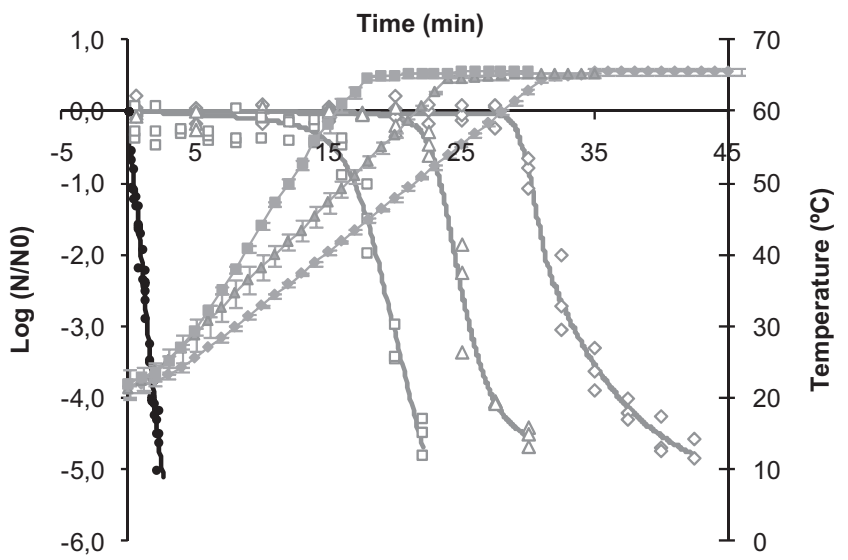

Fig. 2. Thermal inactivation data of $L$. innocua, in liquid medium, using three different temperature profiles: $(\diamond) 1.5^{\circ} \mathrm{C} / \mathrm{min},(\Delta) 1.8^{\circ} \mathrm{C} / \mathrm{min}$ and $(\square) 2.6^{\circ} \mathrm{C} / \mathrm{min}$ and at a constant temperature of $65^{\circ} \mathrm{C}(\bullet)$, using TSAYE as the enumeration medium. Solid lines represent model fits. The bars represent the standard deviation of the temperature histories.
Fig. 1, it should be re-enforced that when temperature reached $65^{\circ} \mathrm{C}$ (for the three temperature profiles used) a significant amount of Listeria cells had membrane damages (since 5 log-cycles of reduction were observed from TSAYE $+\mathrm{NaCl}$ results). This damage was at least partially repaired, since results from TSAYE only reveal a reduction of 2-log cycles for all temperature profiles studied. The same happened for the loss of enzymes functionality (but in less extension), since the difference of the results obtained for the Listeria cells recovered in Palcam Agar and in TSAYE was not so relevant.

The non-isothermal inactivation processes studies were compared to an isothermal treatment, at which the temperature was maintained at $65^{\circ} \mathrm{C}$ (Miller et al., 2009). At a constant temperature of $65^{\circ} \mathrm{C}$, Listeria suffered a 5-log cycles reduction in approximately $2.5 \mathrm{~min}$. Such inactivation did not show either an initial shoulder or a tail tendency (Fig. 2). These results allow concluding that the design of a non-isothermal process should not rely on isothermal-based results.

Results of the Gompertz-inspired model parameters, estimated by fitting Eq. (5) to non-isothermal inactivation (in different media), are presented in Table 1. The adequacy of model fits was tested by residual analysis (i.e. residuals were normally distributed with means equal to zero and constant variance; residuals were random). The coefficient of determination was above 0.97 in all cases. The quality of regression analyses was therefore assessed.

The tail tendency was not evident, since considerable low values of $\log \left(N_{\text {res }} / N_{0}\right)$ estimates (no horizontal asymptote) were obtained. The high values for SHW at 95\% could explain the difference (detected in a very first glance) between the bending towards the asymptote (which value is included in the confidence interval of the estimated parameter) and the estimated value. In such conditions, better results might be obtained if another experimental design was chosen, with more sampling points in the maximum inactivation rate period and at the last stage of the process.

The heating rate effect on parameters' precision was evident. The most precise estimates were obtained when the temperature 


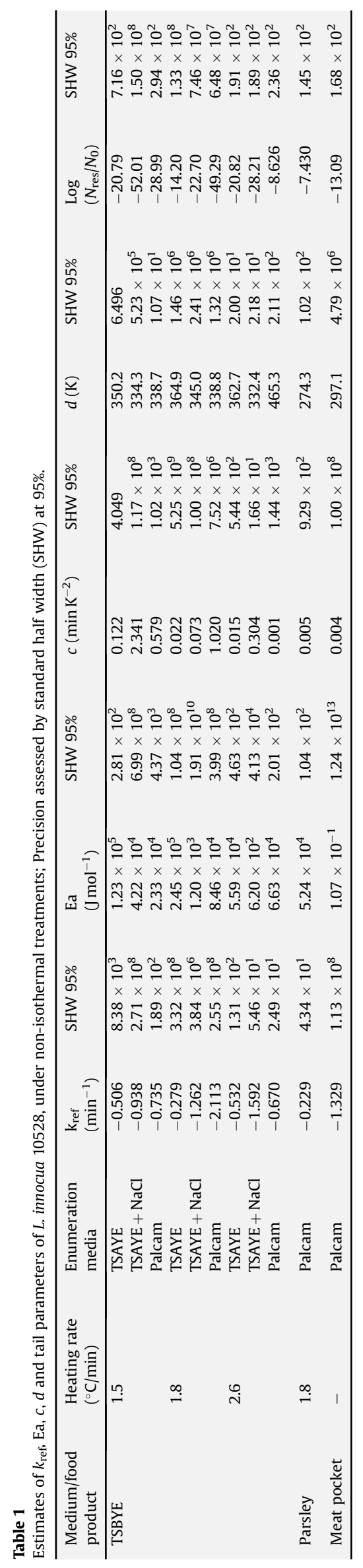

profile with higher heating rate $\left(2.6^{\circ} \mathrm{C} / \mathrm{min}\right)$ was used. This observation is not unexpected when a non-isothermal methodology is used in kinetic studies. Brandão and Oliveira (1997) reported the great influence of the temperature profile on parameters' accuracy and precision, in kinetics of mass transfer. This occurrence may be circumvent by the use of a convenient experimental design, selecting experimental data points and heating rates based on statistical theories (Brandão, Oliveira, \& Cunha, 2001).

The difference observed for the precision of the estimates is not explained by the number of experimental points gathered. In all cases, the number of sampling points averages 30 (and is equivalent for all situations presented in Table 1), which does not limit the fit of the model used (5-parameter model).

In the design of a thermal food process, the microbial responses in media (often attained at laboratorial scale) and in foods should be a concern. To assess those differences, thermal inactivation of L. innocua in parsley was used as a case study. Time-varying temperature conditions were considered, and results were compared to the ones obtained in TSBYE medium (Fig. 3). The linear temperature profile of $1.8^{\circ} \mathrm{C} / \mathrm{min}$ was used (temperature ranging from $20^{\circ} \mathrm{C}$ to $65^{\circ} \mathrm{C}$ ). Besides the sigmoidal tendency observed in both cases, inactivation behaviours were considerably different. In experiments with liquid medium, inactivation started after a shoulder period of 22 min when temperature reached $61^{\circ} \mathrm{C}$. When Listeria was artificially inoculated in parsley, the initial shoulder was reduced to $14 \mathrm{~min}$, corresponding to a temperature of $45^{\circ} \mathrm{C}$. After the shoulder period, the rate of inactivation was higher in TSBYE medium than in the food. Although it is known that food matrixes protect bacterial cells from stressing temperature conditions, this effect was not evident throughout gradual temperature increase when Listeria was in parsley surface. If other kind of food was used, probably even more diverge results would be obtained. For an effective assessment of the factors that influence the microbial response under dynamic temperature conditions, further nonisothermal experiments using different temperature profiles, must be done in a wider range of foods. Food compounds, geometries, type of surfaces, microbial-surface adhesions, are potential variables affecting the microbial responses and generalized conclusions should not be withdrawn without a careful analysis of each situation.

The thermal inactivation kinetics of L. innocua was also followed in a frying process, where frozen meat pockets were used as case studied. The results of microorganism survival and the temperature history monitored at the centre of the product (i.e. the coldest point) during the entire frying process are presented in Fig. 4

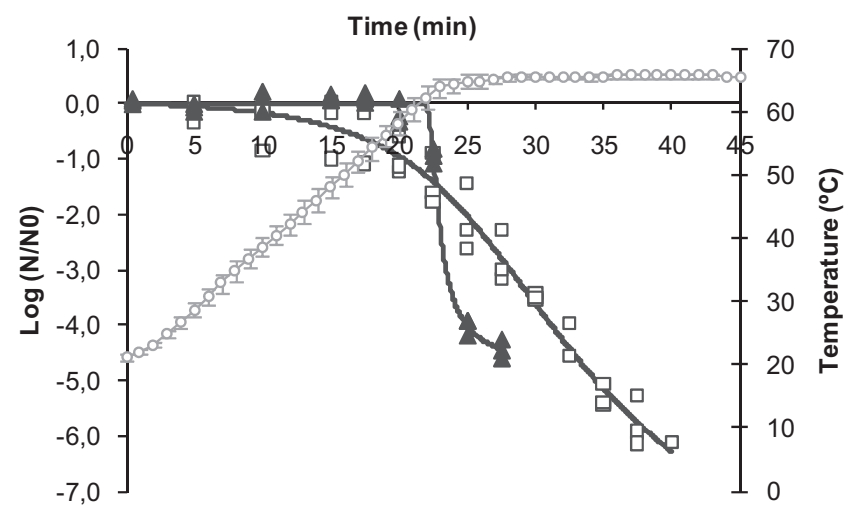

Fig. 3. Thermal inactivation data of $L$. innocua, in liquid medium ( $\boldsymbol{\Delta}$ ) and in parsley ( $\square$ ), using a heating rate of $1.8^{\circ} \mathrm{C} / \mathrm{min}$. Palcam Agar was used as the enumeration medium in both situations. Solid lines represent model fits. The bars represent the standard deviation of the temperature history $(\bigcirc)$. 

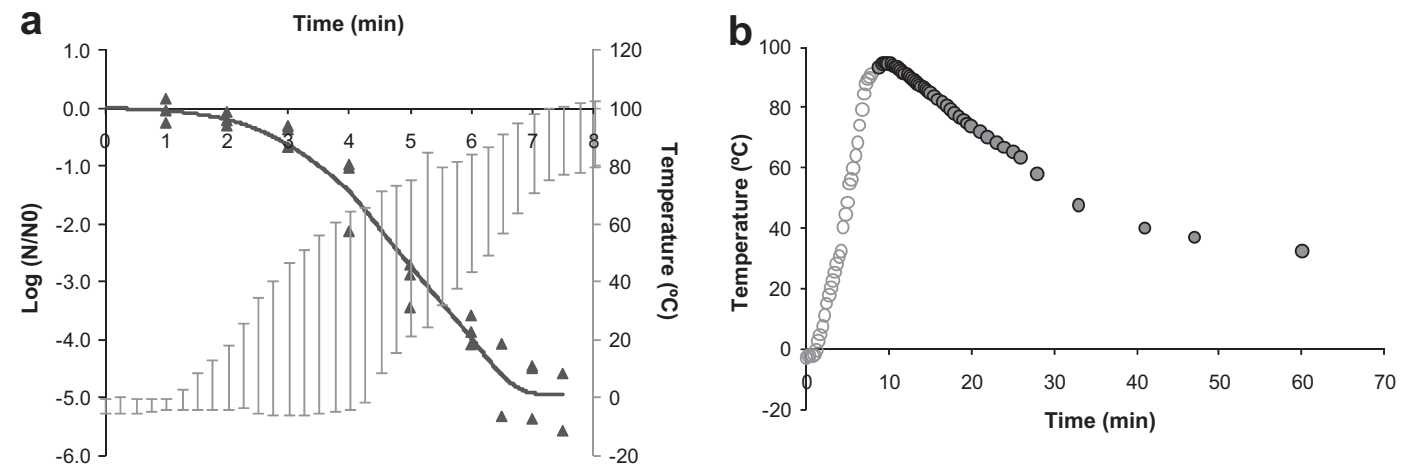

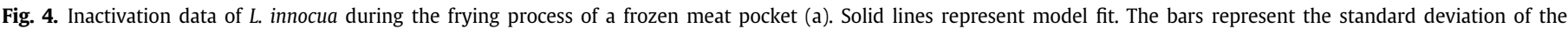
temperature histories $(\bigcirc)$. Temperature history (average values) monitored throughout $1 \mathrm{~h}(\mathrm{~b})$

Results of temperature monitorization reveal a great dispersion of the values. Besides this variation, a sigmoidal tendency of Listeria inactivation was observed throughout the frying process. The inactivation started after a shoulder period of approximately 3 min. At this time the temperature in the meat pocket centre varied between $-2{ }^{\circ} \mathrm{C}$ and $51^{\circ} \mathrm{C}$. It is important to note that besides these are values at the central point, in external meat layers the temperature may have reached higher values and bacterium inactivation may occurred. The problems of predicting the rate of heating and the resulting changes in product quality and sterility are significant, in part because of the complexity of food materials and drawbacks in accurate physical properties estimation (Fryer \& Robbins, 2005).

The effect of the cooling period on bacterial inactivation is also an important topic. Fig. 4(b) shows the temperature evolution in the meat pocket coldest point during and after the frying process (average values). As the meat pocket is removed from the fryer, the heat conduction does not stop in internal layers (unsteady state situation). After 3 min outside the fryer the temperature started to decrease, which proves that the cooling period can partially contribute to the bacteria inactivation at the food centre. Thus, it is of main importance to account for heat transfer phenomena in such processes for accurate predictions of temperature and, consequently, accurate estimations of the kinetics.

Inactivation data of Listeria in parsley and during the frying of meat pockets were fitted with the Gompertz-inspired model (similar to the cases in broth previously discussed). Adequacy of model fits was assessed by residual analyses and coefficient of determination $\left(R^{2}\right.$ values were, respectively, 0.97 and 0.96 for parsley and meat pockets regressions). Estimates of kinetic parameters and related precision are also included in Table 1. For the case of parsley, the temperature profile used had a heating rate of $1.8^{\circ} \mathrm{C} / \mathrm{min}$. Kinetic parameters were estimated with satisfactory precision (please focus on SHW 95\% values). However, it is curious to note that this was the worse choice if experiments were carried out in broth (besides the number of experimental points was identical in both situations). This observation reinforces the role of experimental design previously discussed. In relation to meat pockets frying, although model adequacy was proven, precision of the kinetic parameters was sacrificed.

\section{Conclusions}

The results from the present study indicate that in liquid media $L$. innocua heat resistance under non-isothermal conditions is influenced by the heating rate. A sigmoidal tendency is observed for all the three temperature profiles. However, as heating rate increases, the shoulder period and tail decrease. Results obtained with the three enumeration media reveal that when temperature reached $65^{\circ} \mathrm{C}$ (for all the temperature profiles used), a significant amount of Listeria cells have suffered injury. Broth experiments also highlight the importance of studying the influence of dynamic conditions on the thermal resistance of microorganisms, since the heating-up phases can contribute to an increase in cells thermotolerance.

Results in the food products demonstrated that the product greatly affects bacteria thermal resistance. Data from parsley experiments showed that, although the heat resistance of Listeria increased (when compared to liquid medium), the inactivation began earlier. Results during the frying process of meat pockets underline the importance of a uniform temperature distribution in the entire product. Additionally, it was concluded that, in nonisothermal treatments, not only the heating-up phases are important but also the cooling period.

The results from the present study demonstrated that the enumeration media influenced the Listeria recovery. Particularly for food products, special care must be taken because selective media has to be employed for the inhibition of the product endogena microflora. Hence, the results presented here for parsley and meat pockets are probably underestimated, since some microorganisms can repair themselves if plated in non-selective media.

\section{Acknowledgements}

Fátima A. Miller and Teresa R.S. Brandão gratefully acknowledge their PhD grant (SFRH/BD/11358/2002) and Post-Doctoral grant (SFRH/11580/2002) to Fundação para a Ciência e a Tecnologia (FCT).

\section{References}

Bhaduri, S., Smith, P. W., Palumbo, S. A., Turner-Jones, C. O., Smith, J. L., Marmer, B. S., et al. (1991). Thermal destruction of Listeria monocytogenes in liver sausage slurry. Food Microbiology, 8(1), 75-78.

Brandão, T. R. S., \& Oliveira, F. A. R. (1997). The influence of the temperature increase rate on the accuracy of diffusion parameters estimated under non-isothermal conditions. International Journal of Food Science and Technology, 32, 63-72.

Brandão, T. R. S., Oliveira, F. A. R., \& Cunha, L. M. (2001). Design of experiments for improving the precision in the estimation of diffusion parameters under isothermal and non-isothermal conditions. International Journal of Food Science and Technology, 36, 291-301.

Char, C., Guerrero, S., \& Alzamora, S. M. (2009). Survival of Listeria innocua in thermally processed orange juice as affected by vanillin addition. Food Control, 20(1), 67-74.

Cohen, E., Birk, Y., Mannheim, C. H., \& Saguy, I. S. (1994). Kinetic parameter-estimation for quality change during continuous thermal-processing of grapefruit juice. Journal of Food Science, 59(1), 155-158.

Cole, M. B., Davies, K. W., Munro, G., Holyoak, C. D., \& Kilsby, D. C. (1993). A vitalistic model to describe the thermal inactivation of Listeria monocytogenes. Journal of Industrial Microbiology, 12(3-5), 232-239. 
Fryer, P. J., \& Robbins, P. T. (2005). Heat transfer in food processing: ensuring product quality and safety. Applied Thermal Engineering, 25, 2499-2510.

Gil, M. M., Brandão, T. R. S., \& Silva, C. L. M. (2006). A modified Gompertz model to predict microbial inactivation under time-varying temperature conditions. Journal of Food Engineering, 76(1), 89-94.

Haralampu, S. G., Saguy, I., \& Karel, M. (1985). Estimation of Arrhenius model parameters using 3 least-squares methods. Journal of Food Processing and Preservation, 9(3), 129-143.

Huang, L. (2009). Thermal inactivation of Listeria monocytogenes in ground beef under isothermal and dynamic temperature conditions. Journal of Food Engineering, 90(3), 380-387.

Juneja, V. K., \& Eblen, B. S. (1999). Predictive thermal inactivation model for Listeria monocytogenes with temperature, $\mathrm{pH}, \mathrm{NaCl}$, and sodium pyrophosphate as controlling factors. Journal of Food Protection, 62(9), 986-993.

Juneja, V. K., \& Marks, H. M. (2003). Mathematical description of non-linear survival curves of Listeria monocytogenes as determined in a beef gravy model system at 57.5 to $65^{\circ} \mathrm{C}$. Innovative Food Science and Emerging Technologies, 4(3), 307-317.

Kamat, A. S., \& Nair, P. M. (1996). Identification of Listeria innocua as a biological indicator for inactivation of $L$. monocytogenes by some meat processing treatments. Lebensmittel -Wissenschaft und -Technologie, 29, 714-720.

Linton, R. H., Carter, W. H., Pierson, M. D., \& Hackney, C. R. (1995). Use of a modified Gompertz equation to model nonlinear survival curves for Listeria monocytogenes Scott-A. Journal of Food Protection, 58(9), 946-954.

Marechal, P. A., Martínez de Marnañón, I., Poirier, I., \& Gervais, P. (1999). The importance of the kinetics of application of physical stresses on the viability of microorganisms: significance for minimal food processing. Trends in Food Science E Technology, 10, 15-20.

Margolles, A., Mayo, B., \& Reyes-Gavilán, C. G. (2000). Phenotypic characterization of Listeria monocytogenes and Listeria innocua strains isolated from shortripened cheeses. Food Microbiology, 17, 461-467.

Mendonca, A. F., \& Knabel, S. J. (1994). A novel strictly anaerobic recovery and enrichment system incorporating lithium for detection of heat-injured Listeria monocytogenes in pasteurized milk containing background microflora. Applied and Environmental Microbiology, 60(11), 4001-4008.

Miller, F. A., Brandão, T. R. S., Teixeira, P., \& Silva, C. L. M. (2006). Recovery of heatinjured Listeria innocua. International Journal of Food Microbiology, 112(3), 261-265.

Miller, F. A., Gil, M. M., Brandão, T. R. S., Teixeira, P., \& Silva, C. L. M. (2009). Sigmoidal thermal inactivation kinetics of Listeria innocua in broth: influence of strain and growth phase. Food Control, 20(12), 1151-1157.

Murphy, R. Y., Marks, B. P., Johnson, E. R., \& Johnson, M. G. (2000). Thermal inactivation kinetics of Salmonella and Listeria in ground chicken breast meat and liquid medium. Journal of Food Science, 65(4), 706-710.

Nelder, J. A., \& Mead, R. (1965). A Simplex-method for function minimization. Computer Journal, 7(4), 308-313.

Peleg, M., Penchina, C. M., \& Cole, M. B. (2001). Estimation of the survival curve of Listeria monocytogenes during non-isothermal heat treatment. Food Research International, 34, 383-388.

Piyasena, P., Liou, S., \& McKellar, R. C. (1998). Predictive modelling of inactivation of Listeria spp. in bovine milk during high-temperature short-time pasteurization. International Journal of Food Microbiology, 39, 167-173.

Ramos, J. L., Gallegos, M.-T., Marques, S., Ramos-Gonzalez, M.-I., Espinosa-Urgel, M. \& Segura, A. (2001). Responses of Gram-negative bacteria to certain environmental stressors. Current Opinion in Microbiology, 4(2), 166-171.

Ratkowsky, D. A., Olley, J., McMeekin, T. A., \& Ball, A. (1982). Relationship between temperature and growth-rate of bacterial cultures. Journal of Bacteriology, 149 (1), $1-5$.

Valdramidis, V. P., Geeraerd, A. H., Bernaerts, K., \& Van Impe, J. F. (2006). Microbia dynamics versus mathematical model dynamics: the case of microbial heat resistance induction. Innovative Food Science and Emerging Technologies, 7(1-2), 80-87.

Van Boekel, M. (1996). Statistical aspects of kinetic modeling for food science problems. Journal of Food Science, 61(3), 477-486. 